\title{
La responsabilidad administrativa en materia de urbanismo en el ordenamiento francés
}

\author{
Bernard-Frank Macera $\left({ }^{*}\right)$ \\ María Yolanda Fernández García(**)
}

\begin{abstract}
Sumario: I. INTRODUCCIÓN.- A) Contexto de la realidad indemnizatoria en el ordenamiento jurídico-público francés: la relevancia del sistema de responsabilidad administrativa.- B) La no indemnizabilidad de las "servidumbres urbanísticas": principio y excepciones.- II. LA CONDUCTA ADMINISTRATIVA GENERADORA DEL DANOO.- A) La responsabilidad por culpa de la Administración.- B) La responsabilidad sin culpa de la Administración.- III. EL DAÑO RESARCIBLE Y EL ALCANCE DE LA INDEMNIZACIÓN.- A) El carácter cierto del daño.- B) El carácter directo del daño.- C) El carácter especial y anormal del daño en los casos de responsabilidad sin culpa.- IV. LA IMPUTACIÓN DE LA RESPONSABILIDAD.- A) La identificación de la Administración responsable.- B) Los factores de exoneración de la responsabilidad administrativa.- 1) La culpa del sujeto perjudicado.- 2) La "excepción de riesgo aceptado".
\end{abstract}

\section{INTRODUCGIÓN}

A) Contexto de la realidad indemnizatoria en el ordenamiento jurídicopúblico francés: la relevancia del sistema de responsabilidad administrativa.

En el Derecho francés, de manera muy parecida a lo que ocurre en muchos sistemas jurídicos (entre ellos el español), los derechos indemnizatorios de los particulares se enmarcan en dos instituciones básicas: la expropiación forzosa y la responsabilidad patrimonial de las Administraciones públicas ${ }^{1}$.

\footnotetext{
(*) Profesor Titular de Derecho administrativo de la Universidad de Valladolid.

${ }^{(* *)}$ Profesora Contratada Doctora de Derecho administrativo de la Universidad de Valladolid.

${ }^{1}$ Existe un alto grado de parentesco entre ambas instituciones del Derecho público, ya que las dos obedecen a un fundamento y a unos principios análogos, participando de la nota común de
} 
Ahora bien, la amplitud que poseen una y otra instituciones en el ordenamiento francés es sensiblemente distinta de la que tienen en otros Derechos. Más precisamente, en el país vecino, de acuerdo con la versión clásica de esta figura, la expropiación tiene por objeto esencialmente la transferencia forzosa de la propiedad de los bienes inmuebles. La consecuencia es que los demás sacrificios que se imponen a la propiedad (en concreto, a las diversas facultades que le son inherentes), salvo aquellas restricciones que conducen a "desnaturalizar" o a "vaciar de contenido" dicho derecho, suelen encuadrarse en el sistema general de responsabilidad patrimonial de las Administraciones públicas. Las simples "limitaciones" del derecho de propiedad, como se les suele llamar, no pueden asimilarse a supuestos expropiatorios o ablatorios.

Desde la famosa Sentencia del Tribunal des conflits de 1 de febrero de 1873, "Blanco", la responsabilidad patrimonial de las Administraciones públicas se somete en Francia (al igual que en la mayoría de los países ${ }^{2}$ ) a un régimen específico, distinto del que corresponde a la responsabilidad de los sujetos privados. Tres son los requisitos que condicionan la aparición de una carga administrativa indemnizatoria: un daño sufrido por un sujeto, una acción u omisión de la Administración y una relación de causalidad entre el primero y la segunda. No nos detendremos en estas condiciones. Su estudio es lo suficientemente generalizado y exhaustivo como para liberarnos de la necesidad de someterlas a una tarea analítica.

B) La no indemnizabilidad de las "servidumbres urbanísticas": principio y excepciones.

El Derecho urbanístico francés consagra desde hace muchos años el principio general de la no indemnizabilidad de las "servidumbres urbanísticas". En

garantizar la integridad patrimonial de los particulares frente a ciertas actuaciones de los Poderes públicos. Ahora bien, existen importantes diferencias entre ellas. Se puede afirmar, de manera sintética, que la distinción esencial reside en el hecho de que la responsabilidad abarca todos aquellos daños a terceros que causen actuaciones públicas de manera derivada o incidental, no como su objeto directo, mientras que la actividad ablatoria o expropiatoria viene constituida por el conjunto de actuaciones públicas, normativas o resolutorias, dirigidas voluntariamente a la privación total o parcial de un derecho o de un interés patrimonial legítimo de un sujeto determinado (o de un grupo de sujetos determinables) para la satisfacción de ciertas finalidades públicas, por causa justificada y proporcionada de utilidad pública o interés social. Lo más característico de esta actividad es que consiste en la imposición directa y deliberada de un sacrificio, de una limitación o de una restricción que puede considerarse como especial o singular, si se compara con el tratamiento que se da a los demás sujetos que se encuentran en las mismas circunstancias.

${ }^{2} \mathrm{Al}$ menos en aquellos que disponen de un sistema legal cortado inicialmente con el patrón del «régime administratif». 
el ordenamiento vigente, el principio mencionado se proclama en el art. L. 160-5 del Código de Urbanismo (en adelante, CU), que establece literalmente que "No darán derecho a indemnización las servidumbres que se establezcan en aplicación del presente código en materia de viales, higiene o estética o en otros ámbitos, y relativas, en particular, a la utilización del suelo, la altura de las edificaciones, la proporción entre las superficies construidas y las no construidas en cada parcela, la prohibición de edificar en determinadas zonas y a los lados de determinadas vías, la distribución de los inmuebles entre las diversas zonas (...)”3.

El alcance de dicho precepto se resume en la idea de que los administrados no pueden reclamar la reparación de los perjuicios causados por el establecimiento o la imposición de "servidumbres urbanísticas" (restricciones a las que los Poderes públicos someten la propiedad privada en beneficio del interés general), a no ser que consigan demostrar la existencia de una actuación ilícita de la Administración pública. Desde una perspectiva más amplia, como destaca MODERNE, ello implica que los propietarios no pueden obtener una reparación por la pérdida de valor sufrida en su patrimonio inmobiliario ${ }^{4}$, incluso cuando ésta resulta de una prohibición de edificar (servidumbre “non aedificandi”) ${ }^{5}$. Además, como precisa este autor, no existen mecanismos de compensación que permitan equilibrar en alguna medida las plusvalías y las cargas generadas por las limitaciones urbanísticas ${ }^{6}$. Finalmente, cabe añadir que el art. L. 160-5 hace imposible la aplicación de cualquier otro sistema de indemnización.

Ahora bien, el Derecho urbanístico francés reconoce la posibilidad de descartar la regla de la no indemnizabilidad de las "servidumbres urbanísti-

\footnotetext{
${ }^{3}$ Sobre este principio, por ejemplo, vid. J.B. AUBY, «Le principe de non-indemnisation des servitudes instituées par application du Code de l'urbanisme», Droit et Ville 10 (1980), pp. 171 ss. Vid. también, J.B. AUBY y H. PÉRINET-MARQUET, Droit de l'urbanisme et de la construction, $4^{a}$ ed., Montchrestien, Paris, 1995, pp. 131 ss.; F. BOUYSSOU, «L'indemnisation des servitudes d'intérêt public», Droit et Ville 30 (1990), p. 120 ss.; R. HOSTIOU, «La non-indemnisation des servitudes d'urbanisme», Actualité Juridique. Droit Administratif 1993, pp. 27 ss.; G. LIET-VEAUX, «L'indemnisation des sujétions d'urbanisme, prélude à une reforme législative», Revue Administrative 221 (1984), pp. 460 ss.; F. MÉLIN-SOUCRAMANIEN y J. TRÉMEAU, «Droit constitutionnel de l'urbanisme», JCP Administratif, Fasc. 1454 (1994), no 22; F. MODERNE, «Propiedad privada y urbanismo», en vol. col., Propiedad, expropiación y responsabilidad (la garantía indemnizatoria en el Derecho europeo y comparado), coord.: J. BARNÉS VÁZQUEZ, Tecnos, Madrid, 1996, pp. 311-312.

4 «Propiedad privada y urbanismo», cit., p. 311.

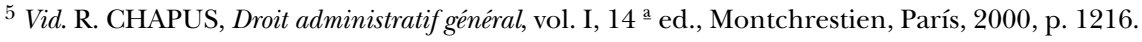

6 «Propiedad privada y urbanismo», cit., pág. 312.
} 
cas". En efecto, por un lado, el propio art. L. 160-5 CU contiene excepciones al principio que él mismo proclama. Más precisamente, dicho precepto establece que "una indemnización deberá otorgarse en el supuesto en que dichas servidumbres conlleven una vulneración de derechos adquiridos o una modificación del estado anterior de los lugares dando lugar a un daño directo, material y cierto. En el caso en que no se llegue a un acuerdo amistoso, esta indemnización habrá de fijarse por el tribunal administrativo, que deberá tener en cuenta la plusvalía que resulte para los bienes inmuebles de la realización del proyecto de ordenación"7.

Por otra parte, la jurisprudencia contencioso-administrativa ha ido delimitando otros supuestos indemnizatorios, aplicando al ámbito del urbanismo los principios generales del sistema de responsabilidad administrativa destacados a lo largo de aproximadamente ciento treinta años de jurisprudencia, desde la antes citada Sentencia del Tribunal des conflits de 1 de febrero de 1973, "Blanco".

${ }^{7}$ La jurisprudencia ofrece algunos ejemplos de la primera situación, que se refiere, como acaba de exponerse, a la imposición a la Administración pública de un deber resarcitorio por la vulneración de derechos adquiridos. En particular, se indemnizan las inversiones realizadas cuando la construcción de una obra legalmente autorizada queda interrumpida como consecuencia de una alteración del planeamiento (vid. por ejemplo las Sentencias del Conseil d'État de 13 de febrero de 1987, «Anrigo», Actualité Juridique. Droit Administratif 1987, p. 596; y de 6 de marzo de 1987, «Société en nom collectif Guillaume, Cerrito, de Montera et Compagnie», Droit Administratif 1987, no 260). Del mismo modo, cabe otorgar una indemnización al titular de una licencia de explotación de una cantera que ha de interrumpir y cesar su actividad por el establecimiento de una servidumbre urbanística nueva (vid. la Sentencia del Conseil d'État de 10 de junio de 1988, «Établissements Bonnargent-Goyon», Actualité Juridique. Droit Administratif 1989, p. 54). Finalmente, ha de resarcirse al propietario que no ha podido vender su parcela como consecuencia de la denegación por la Administración de la autorización de transmisión de la licencia de edificación, motivada por una revisión pendiente del planeamiento en virtud de la cual la parcela en cuestión iba a convertirse en suelo no urbanizable (vid. la Sentencia del Conseil d'État de 8 de noviembre de 1989, «Degouy», Actualité Juridique. Droit Administratif 1990, p. 97). En cambio, la segunda situación descrita por el art. L. $160.5 \mathrm{CU}$ (es decir, la modificación del estado anterior de las cosas) no ha dado lugar a supuestos indemnizatorios. En realidad, esta disposición carece de alcance práctico.

${ }^{8}$ Sobre el tratamiento jurisprudencial de la responsabilidad patrimonial de las Administraciones públicas en materia de urbanismo, además de la bibliografía citada en el presente artículo, sin pretensión de exhaustividad, vid. J.B. AUBY, «La responsabilité de la puissance publique en matière d'urbanisme: jurisprudence 1986-1987», Les Petites Affiches, 4 de mayo 1988, pp. 9 ss.; J.B. AUBY, «La responsabilité de la puissance publique en matière d'urbanisme: jurisprudence 1988», Les Petites Affiches, 1 de mayo de 1989, pp. 12 ss.; J.B. AUBY, «La responsabilité de la puissance publique en matière d'urbanisme: jurisprudence 1989», Les Petites Affiches, 31 de octubre de 1990, pp. 11 ss.; J.B. AUBY, «La responsabilité de la puissance publique en matière d'urbanisme: jurisprudence 1990», Les Petites Affiches, 3 de julio de 1991, pp. 18 ss.; G. CALONEC, «Les limites de la responsabilité administrative dans le contentieux de l'urbanisme», Actualité Juridique. Propriété Immobilière, 1979, pp. 15 ss.; J. MOREAU, «Cinq années de jurisprudence relative à la responsabilité de l'État en matière d'urbanisme», Cahiers du CFPC 15 (1985), pp. 67 ss. 
Son a dichos supuestos que vamos a dedicar el presente estudio. Para abordar su tratamiento, hemos optado por analizar con detalle los requisitos, elementos y mecanismos que articulan la puesta en juego de la responsabilidad: la conducta administrativa generadora del daño (II), la lesión resarcible —con especial referencia al alcance de la indemnización-(III) y la imputación de la carga indemnizatoria (IV) ${ }^{9}$.

\section{LA CONDUCTA ADMINISTRATIVA GENERADORA DEL DAÑO}

La responsabilidad en la que puede incurrir la Administración pública en materia de urbanismo, en principio, viene causada por una culpa, es decir, una conducta ilícita o un funcionamiento defectuoso de sus servicios (A). Sin embargo, en determinados supuestos - muy escasos-, se reconoce la responsabilidad administrativa sin culpa (B).

\section{A) La responsabilidad por culpa de la Administración.}

En primer lugar, la culpa susceptible de dar lugar a la responsabilidad de la Administración pública puede consistir en una ilegalidad como, por ejemplo, el otorgamiento, la revocación o la denegación ilícita de una licencia de edificación ${ }^{10}$ o de parcelación ${ }^{11}$; una orden ilegal de suspensión de las obras ${ }^{12}$; etc. ${ }^{13}$

\footnotetext{
9 Teniendo en cuenta que no presenta ninguna especificidad relevante en materia de urbanismo, no entraremos en el estudio de la acción de responsabilidad. Nos remitimos a las obras generales que se han referido a dicha cuestión.

${ }^{10}$ Sobre la responsabilidad patrimonial de la Administración pública por el otorgamiento ilegal de una licencia de edificación (que perjudica a terceros o al propio solicitante -en particular, en caso de anulación posterior por el juez o de revocación por la Administración-), ténganse presentes, entre otras muchas, las Sentencias del Conseil d'État de 12 de marzo de 1990, «Madame Gallichet» (Les Petites Affiches, 3 de julio de 1991, p. 20, crón. J.B. Auby); y de 25 de abril de 2003, «Société Civile Immobilière Le Val de Valescure». Sobre la denegación ilegal de las licencias de edificación, como supuesto indemnizatorio, vid. la Sentencia de la Cour administrative d'appel de Nantes de 30 de diciembre de 1996, «M. Leboissetien» (Actualité Juridique. Droit Administratif 1997.312). En relación con la revocación ilegal de las licencias de edificación, vid. por ejemplo las Sentencias del Conseil d'État de 30 de septiembre de 1983, «Calle» (Recueil Lebon 859); y de 2 de marzo de 1984, «Époux Saada» (Gazette du Palais 1985.1). En la doctrina, vid. P. HOCREITIERE, «L'annulation du refus illégal du permis de construire», Droit Administratif, marzo 1994, p. 1.

11 Sobre la responsabilidad patrimonial de la Administración pública por otorgamiento ilegal de una licencia de parcelación, ténganse en cuenta las Sentencias del Conseil d'État de 9 de julio de 1990, «Société Sorrel Chamoux» (Les Petites Affiches, 3 de julio de 1991, p. 20, crón. J.B. Auby); y de 26 de noviembre de 1993, «Société civile immobilière Les Jardins de Bibemus» (Recueil Lebon 327).
} 
Hemos de precisar, en segundo lugar, que los simples errores de apreciación cometidos por la Administración pública son susceptibles de generar su responsabilidad patrimonial por culpa ${ }^{14}$. Es el caso, por ejemplo, cuando la Administración no subordina a condiciones especiales una licencia que se otorga a un particular y que le permite edificar en una zona expuesta a un riesgo natural (inundaciones, aludes, etc.) ${ }^{15}$.

En tercer lugar, finalmente, el deber de indemnizar a los sujetos afectados puede derivar también del funcionamiento defectuoso de los servicios de la Administración. Algunos supuestos a los que aquí se alude son, por ejemplo, la inclusión de información errónea en los certificados de urbanismo ${ }^{16}$, el otorgamiento de una licencia de edificación ambigua e insuficientemente

Vid. también las Sentencias de la Cour administrative d'appel de París de 27 de abril de 1999, «Commune de Saint-Chéron et autres» (Revue française de droit administratif 1999.1076). Sobre la denegación ilegal de las licencias de parcelación, como supuesto indemnizatorio, vid. la Sentencia de la Cour administrative d'appel de Lyon de 19 de marzo de 1990, «Mmes Moriando et Garro» (Les Petites Affiches, 3 de julio de 1991, p. 20, crón. J.B. Auby).

12 Ténganse presentes las Sentencias del Conseil d'État de 28 de octubre de 1987, «Société Civile Immobilière Résidence Neptune»; y de 3 de noviembre de 1989, «Ministre de l'Urbanisme et du Logement, Saint-Yrieix» (Les Petites Affiches, 31 de octubre de 1990, p. 13, crón. J.B. Auby).

${ }^{13}$ Para más supuestos, vid. por ejemplo, J.B. AUBY y H. PÉRINET-MARQUET, Droit..., cit., pp. 133-135. Vid. también, H. JACQUOT, Droit de l'urbanisme, 2a ed., Dalloz, Paris, 1989, pp. 673-674; R. SAVY, Droit de l'urbanisme, PUF, Paris, 1981, pp. 667-668.

14 Vid. la Sentencia del Conseil d'État de 26 de enero de 1973, «Driancourt c/. Ville de Paris» (Actualité Juridique. Droit Administratif 1973.273, crón. Cabannes y Léger). Vid. también, J.C. LORTHE, «La responsabilité de la puissance publique en matière de permis de construire», Revue d'Economie et de Droit Immobilier 77 (1978), pp. 3-5; P. COMTE, «Réflexions sur l'utilisation de l'erreur manifeste d'appréciation dans le contentieux des plans d'occupation des sols", Revue française de droit administratif 1/1990, pp. 72 ss.; B. LIME, «Réflexions sur l'utilisation de l'erreur manifeste dans le contentieux du permis de construire», Revue française de droit administratif 6/1989, pp. 985 ss.; L. YOUSRY, «Le contrôle de l'erreur manifeste en matière de zonage des plans d'occupation des sols», Revue de Droit Immobilier 4 (1985), pp. 335 ss.

15 Téngase presente la Sentencia del Conseil d'État de 26 de junio de 1996, «M. Iogna et autres». Vid. también la Sentencia de la Cour administrative d'appel de París de 28 de junio de 1996, «Époux Mouthon» (Bulletin de Jurisprudence de Droit de l'Urbanisme 1996, no 4, p. 298).

${ }^{16}$ Los «certificats d'urbanisme» constituyen documentos solicitados por los particulares, en los que la Administración proporciona informaciones relativas a la situación de los terrenos (art. L. 410-1, ap. $\left.1^{\circ}, \mathrm{CU}\right)$ o a la realización de un proyecto (art. L. 410-1, ap. 2ㅜ, CU). Sobre el supuesto indemizatorio aquí contemplado, vid. por ejemplo la Sentencia del Conseil d'État de 3 de octubre de 1990, "Ministre de l'Équipement, du Logement, de l'Aménagement du Territoire et des Transports c/. Monsieur et Madame Valleret» (Les Petites Affiches, 3 de julio de 1991, p. 20, crón. J.B. Auby). 
$\operatorname{motivada}^{17}$, el sometimiento de una licencia a exigencias desproporcionadas $^{18}$, la creación de expectativas o compromisos no respetados ${ }^{19}$, las demoras injustificadas en el otorgamiento de certificados o licencias que no pueden beneficiarse del mecanismo del silencio positivo ${ }^{20}$, la oposición a la ejecución de una licencia legalmente otorgada ${ }^{21}$, la aprobación de un proyecto de ordenación anulado con posterioridad por la jurisdicción contencioso-administrativa y que haya creado expectativas ${ }^{22}$, etc ${ }^{23}$. Hemos de señalar aquí que el supuesto antes aludido de la no subordinación a condiciones especiales de una licencia otorgada a un particular y que le permite edificar en una zona expuesta a un riesgo natural (inundaciones, aludes, etc.), que ha sido considerado con frecuencia por la jurisprudencia, como hemos explicado, por un error de apreciación, ha sido interpretado también en algunas ocasiones por la jurisdicción contencioso-administrativo como un supuesto específico de funciona-

\footnotetext{
17 Vid. la Sentencia del Conseil d'État de 3 de febrero de 2003, «M. Weber» (Actualité Juridique. Droit Administratif 2003.1127).

18 Téngase en cuenta la Sentencia del Conseil d'État de 20 de enero de 1988, «MELATT c/. Posado».

19 Téngase presente la Sentencia del Conseil d'État de 28 de junio de 1985, «Société Civile Immobilière de la Chalp», en la que se reconoce la responsabilidad patrimonial de la Administración por la orden impuesta al propietario de una casa situada en una zona de montaña de no ocuparla durante el periodo de invierno, cuando la licencia correspondiente se había otorgado sin condiciones ni límites. Vid. también la Sentencia del Conseil d'État de 26 de octubre de 1973, "Société Civile Immobilière Résidence Arcole» (Recueil Lebon 601; Recueil Dalloz 1974.446, nota Girod; Revue de Droit Public 1975.527). En este pronunciamiento se reconoce la responsabilidad patrimonial del Municipio por haber incitado una sociedad a edificar antes de denegar la licencia correspondiente. Más recientemente, vid. la Sentencia de 16 de noviembre de 1998, «M. Sille» (Recueil Dalloz 1999.15; Revue française de droit administratif 1999.267). En general, sobre este tema, vid. J.C. LORTHE, «La responsabilité...», cit., pp. 6-7.
}

20 Téngase en cuenta la Sentencia del Conseil d'État de 12 de marzo de 1986, «Demange». Más recientemente, vid. la Sentencia de la Cour administrative d'appel de París de 27 de abril de 1999, «Société Civile Immobilière Le Cèdre» (Revue française de droit administratif 2000.191). Vid. sobre este tema, J.C. LORTHE, «La responsabilité...», cit., pp. 5-6.

21 Vid. la Sentencia del Conseil d'État de 24 de julio de 1987, «Société immobilière de Verneuil-Vernouillet» (Les Petites Affiches, 23 de diciembre de 1987, p. 3, concl. Guillaume).

22 Vid. la Sentencia de la Cour administrative d'appel de París de 27 de noviembre de 2001, «Société financière de la Porte Maillot» (Revue française de droit administratif 2002.421).

23 Para más supuestos indemnizatorios, vid. por ejemplo, H. JACQUOT, Droit..., cit., p. 674. Vid. también, R. SAVY, Droit..., cit., p. 668; J.B. AUBY y H. PÉRINET-MARQUET, Droit..., cit., pp. 133-135. 
miento defectuoso de los servicios de la Administración constitutivo de responsabilidad, al igual que los demás ejemplos que acabamos de enumerar ${ }^{24}$.

B) La responsabilidad sin culpa de la Administración

La jurisdicción contencioso-administrativa no ha reconocido la responsabilidad sin culpa de la Administración pública más que en contadas ocasiones $^{25}$. La razón que suele esgrimirse para explicar la escasa relevancia de esta modalidad de responsabilidad en materia de urbanismo es que la ordenación de los terrenos y de las construcciones es en sí misma discriminatoria y, por tanto, los inconvenientes y perjuicios a los que da lugar dicha actividad no suelen reunir los requisitos que condicionan la aparición del deber de la Administración de compensar o corregir sus consecuencias gravosas y negativas, es decir, como veremos, la especialidad y, sobre todo, la anormalidad ${ }^{26}$. Además, como señala Odent, "es probable que el juez administrativo no quiera paralizar la actividad de Administración mediante la frecuente puesta en juego de una responsabilidad que acabaría por costar muy caro a la colectividad"27.

Los supuestos indemnizatorios a los que aquí se hace referencia se concretan esencialmente en tres tipos de circunstancias: la inactividad (lícita) de la Administración pública a la hora de iniciar el procedimiento destinado a castigar infracciones urbanísticas y a ordenar la demolición de las obras reali-

\footnotetext{
${ }^{24}$ En relación con las zonas «inundables», vid. la Sentencia del Conseil d'État de 2 de octubre de 2002, «Ministre de l'Équipement, des Transports et du Logement c/. Époux Grondin» (Actualité Juridique. Droit Administratif 2003.143, nota Deffigier). En este pronunciamiento, la culpa que se imputa a la Administración deriva del hecho de que el carácter «inundable» de la zona en cuestión era conocido por la autoridad pública. En la misma línea, con anterioridad, vid. la Sentencia de la Cour administrative d'appel de Lyon de 9 de julio de 1990, «Commune de Bourg-Saint-Maurice». A propósito de zonas expuestas a aludes, téngase presente la Sentencia del Conseil d'État de 16 de junio de 1989, «Association Le ski alpin Murois» (Recueil Lebon 141).

25 Vid. J.C. LORTHE, «La responsabilité...», cit., p. 7.

${ }^{26}$ Como explica J.B. AUBY («Responsabilité en matière d'urbanisme», en Répertoire Dalloz de la responsabilité de la puissance publique, $\mathrm{n}^{\circ}$ 63), la jurisprudencia suele considerar que «la vida urbana y el desarrollo urbano comportan un grado elevado de inconvenientes normales».

${ }^{27}$ La politique immobilière du juge administratif, Paris, 1974, p. 144 (cit. por J.C. LORTHE, «La responsabilité...», cit., p. 7).
} 
zadas $^{28}$, la modificación de una licencia de edificación legalmente otorgada con el fin de permitir la salvaguardia de restos arqueológicos descubiertos en la parcela en cuestión ${ }^{29}$ y, finalmente, la alteración de proyectos de ordenación que hace imposible o inservible la realización de operaciones parciales de ordenación ${ }^{30}$. Que sepamos, no existen más casos que los que acabamos de mencionar. Además, hemos de advertir que el primer supuesto mencionado ya no puede considerarse como un ejemplo de responsabilidad sin culpa (salvo, quizá, en lo que se refiere a la fase de la demolición de las obras realiza$\operatorname{das}^{31}$ ), habida cuenta de que la represión de las infracciones urbanísticas se configura desde la Ley no 76-1285, de 31 de diciembre de 1976, de Urbanismo, como un deber legal, con lo que su incumplimiento constituye en realidad un caso de responsabilidad culposa.

\section{EL DAÑO RESARCIBLE Y EL ALCANCE DE LA INDEMNIZA- CIÓN}

Para que su responsabilidad patrimonial pueda reconocerse, no basta con que la Administración haya cometido una culpa o vulnerado el principio de igualdad ante las cargas públicas, sino que es necesario que haya causado con ello un perjuicio que reúna ciertos caracteres. Más precisamente, en materia de urbanismo, al igual que en los demás ámbitos de la responsabilidad administrativa, la jurisdicción sólo considera como resarcibles los daños ciertos (A), directos (B) y, además, si estamos hablando de responsabilidad sin culpa, anormales y especiales $(\mathrm{C})$.

${ }^{28}$ Téngase presente, por ejemplo, la Sentencia del Conseil d'État de 20 de marzo de 1974, «Ministre de l'Aménagement du Territoire c/. Navarra» (Recueil Lebon 200, concl. Rougevin-Baville; Actualité Juridique. Droit Administratif 1974.303, crón. Franc y Boyon; Recueil Dalloz 1974.481, nota Gilli; Revue de Droit Public 1974.930, nota de Soto). Antes de este pronunciamiento, se descartaba expresamente la responsabilidad sin culpa de la Administración.

${ }^{29}$ Téngase en cuenta la Sentencia del Conseil d'État de 20 de enero de 1989, «Ministre de la Culture et de la Communication c/. Société Civile Immobilière Villa Jacob» (Droit Administratif 1989, no 145). Sobre este aspecto, vid. P. MARTEL, «La responsabilité administrative du fait des fouilles archéologiques», JCP 1993-1-3706

${ }^{30}$ Vid. por ejemplo la Sentencia del Conseil d'État de 17 de marzo de 1989, «Ville de Paris» (Recueil Lebon 96). En general, sobre estos supuestos indemnizatorios en el marco de la responsabilidad administrativa sin culpa, vid. por ejemplo, H. JACQUOT, Droit..., cit., pp. 674-675. Vid. también, J.B. AUBY y H. PÉRINET-MARQUET, Droit..., cit., p. 133; R. SAVY, Droit..., cit., pp. 668-669. hault».

${ }^{31}$ Téngase presente la Sentencia del Conseil d'État de 17 de diciembre de 1980, «MECV c/. Mé- 
A) El carácter cierto del daño

El carácter cierto del daño se concreta en la condición de que debe tratarse de perjuicios actuales o ineludibles cuya realidad viene claramente establecida y demostrada ${ }^{32}$, como, por ejemplo, en principio, los gastos que resultan inservibles como consecuencia de la revocación o anulación del título -en principio, una licencia-que amparaba el proyecto del particular (honorarios de los arquitectos, gastos de acondicionamiento de terrenos, etc. ${ }^{33}$ ), la pérdida de valor y la consiguiente disminución del precio de venta de una parcela reclasificada como suelo no urbanizable ${ }^{34}$, el mayor coste de ejecución de las obras causado por un retraso injustificado o por una actuación ilícita de la Administración ${ }^{35}$, la frustración de alquileres ${ }^{36}$, la inmovilización del capital provocada por una actuación culposa de la Administración (como la suspensión ilegal de las obras ${ }^{37}$, la frustración de beneficios vinculados a la explotación de un local comercial ${ }^{38}$, etc.

Por ello, la jurisdicción contencioso-administrativa, en principio, se niega a indemnizar los perjuicios meramente eventuales ${ }^{39} \mathrm{y}$, en particular, los casos

32 Vid. R. SAVY, Droit..., cit., pp. 669-670. En la jurisprudencia, vid. la Sentencia del Conseil d'État de 24 de noviembre de 1971, «Thibault» (Recueil Lebon 1197).

${ }^{33}$ Vid. la Sentencia del Conseil d'État de 16 de noviembre de 1998, «M. Sille» (Revue française de droit administratif 1999.267).

34 Téngase presente la Sentencia del Conseil d'État de 16 de enero de 1987, «Commune de Pierrévert c/. Lasprèches» (Droit Administratif 1987, no 126).

35 Vid. la Sentencia del Conseil d'État de 10 de marzo de 1971, «Sieur Hamon et Ministre de l'Équipement et du Logement» (Droit Administratif 1971, nº 114).

36 Téngase presente la Sentencia del Conseil d'État de 15 de diciembre de 1971, «Société Le Vald'Oises (Recueil Lebon 775).

37 Vid. la Sentencia del Conseil d'État de 12 de noviembre de 1975, «Société Civile Immobilière Résidence du Pays d'Oc» (Droit Administratif 1975.395).

38 Téngase en cuenta la Sentencia del Conseil d'État de 25 de enero de 1978, «Ministre de l'Aménagenement, du Logement et du Tourisme c/. Société Pavita» (Recueil Dalloz 1979, nㅡㄴ 144, nota Moderne).

${ }^{39}$ Vid. la Sentencia del Conseil d'État de 24 de noviembre de 1971, «Ministre de l'Équipement et du Logement c/. Thibault» (Recueil Lebon 1238). En la doctrina, vid. J.C. LORTHE, «La responsabilité...», cit., p. 12. 
de "lucrum cessans" en el ámbito comercial ${ }^{40}$, como, por ejemplo, la falta de rendimiento y los beneficios frustrados en la explotación de bienes inmuebles no edificados como consecuencia de la denegación ilegal de una licencia o del retraso injustificado de la Administración ${ }^{41}$. Sin embargo, hemos de señalar que el Conseil d'État ha ido flexibilizando su jurisprudencia en el sentido de que ha considerado como resarcible la frustración de beneficios vinculados a operaciones inmobiliarias ${ }^{42}$, matizando con ello su empeño (tan vano como difícil de materializar con equidad) por no favorecer la realización de beneficios exclusivamente especulativos, como manifestación de su -autoatribuido- papel de "regulador e incluso moralizador" en materia de urbanismo ${ }^{43}$.

Hemos de señalar aquí que la jurisprudencia considera resarcibles ciertos daños calificados como morales. Así, admite la indemnización de los perjuicios en las condiciones de vida ocasionados, por ejemplo, por el hecho de tener que seguir viviendo en una casa inadecuada en relación con las necesidades de los interesados ${ }^{44}$, por la carga de tener que acudir de manera reiterada a la vía judicial ${ }^{45}$, etc.

B) El carácter directo del daño

El carácter directo del daño (se entiende que éste debe ser la consecuencia normal y directa de la conducta de la Administración) es sin duda el re-

\footnotetext{
40 Vid. la Sentencia del Conseil d'État de 16 de noviembre de 1998, «M. Sille» (Revue française de droit administratif 1999.267).

41 Téngase presente la Sentencia del Conseil d'État de 6 de marzo de 1987, «Société en nom collectif Guillaume, Cerrito, de Montéra et compagnie» (Droit Administratif 1987, no 260).

42 Ténganse en cuenta las Sentencias del Conseil d'État de 24 de octubre de 1990, «Société Civile Immobilière Le Grand Large» (Les Petites Affiches, 3 de julio de 1991, p. 21, crón. J.B. Auby). Vid. sobre este tema, por ejemplo, L. BRUNEAU, «Indemniser le bénéfice escompté ? Une nouvelle jurisprudence du Conseil d'État», Etudes Foncières, 1985, no 27

${ }^{43}$ Sobre esta actitud del Conseil d'État, vid. J.P. TAUGOURDEAU, «Le caractère certain et direct du préjudice en matière de responsabilité extracontractuelle de la puissance publique», $A c$ tualité Juridique. Droit Administratif, 1974, p. 521.

${ }^{44}$ Téngase en cuenta la Sentencia del Conseil d'État de 21 de julio de 1989, «Cocorel» (Les Petites Affiches, 31 de octubre de 1990, nota J.B. Auby).

45 Téngase presente la Sentencia de la Cour administrative d'appel de Nancy de 12 de diciembre de 1991, «Époux Delobette» (Recueil Lebon 1263).
} 
quisito que la jurisdicción contencioso-administrativa interpreta de manera más estricta y restrictiva ${ }^{46}$.

Como ejemplo de estimación de la acción de responsabilidad, cabe subrayar que el Conseil d'État impone el deber de resarcir la pérdida de alquileres sufrida por el propietario de un bien inmueble arrendado a una empresa comercial, siendo abocada ésta a la quiebra como consecuencia del otorgamiento ilegal de una licencia de edificación a una empresa competidora ${ }^{47}$. Por el contrario, se considera en el mismo asunto que la disminución del valor del inmueble no es imputable a la Administración.

Conviene destacar aquí que en la mayoría de los supuestos en los que se reconoce la responsabilidad patrimonial de la Administración pública, la jurisdicción contencioso-administrativa, de acuerdo con su tendencia general en materia de urbanismo y en contradicción directa con el principio de reparación íntegra de los perjuicios, limita de modo muy estricto el alcance de la indemnización. Así, por ejemplo, cuando se anula la denegación ilegal de una licencia de edificación pero la entrada en vigor de una nueva ordenación impide el otorgamiento de otra licencia, el demandante sólo puede solicitar la indemnización de los gastos realizados en concepto de honorarios de arquitectos. En efecto, no entran en la categoría de los daños directos los honorarios notariales, la disminución del valor del bien, la frustración de los beneficios esperados de la venta de las viviendas que tenían que edificarse, etc. ${ }^{48}$.

En realidad, los ejemplos más frecuentes son los que reflejan pronunciamientos desestimatorios de la acción de responsabilidad ${ }^{49}$. Así, el Conseil d'État se ha negado a reconocer un derecho indemnizatorio a un arquitecto que alegaba la existencia de unos perjuicios económicos causados por la denegación ilegal de una licencia de edificación a su cliente, en la medida en que entre la falta administrativa y el daño sufrido se interpone un contrato celebra-

46 Vid. en tal sentido, H. JACQUOT, Droit..., cit., p. 676. Vid. también, J.C. LORTHE, «La responsabilité...», cit., p. 11; R. SAVY, Droit..., cit., p. 671.

47 Téngase presente la Sentencia de 15 de enero de 1975, «Marion» (Actualité Juridique. Droit Administratif 1975.188).

48 Téngase en cuenta la Sentencia del Conseil d'État de 28 de enero de 1983, «SA Aménagement touristique de l'Ouest» (Actualité Juridique. Propriété Immobilière 1984.539, nota R. Hauriou).

49 Vid. los ejemplos citados por R. SAVY, Droit..., cit., pp. 670-671. Vid. también, H. JACQUOT, Droit..., cit., pp. 676-677. 
do entre el arquitecto y su cliente del que no es parte la Administración pública $^{50}$. Del mismo modo, se considera que el perjuicio sufrido por un propietario como resultado de la decisión de un promotor inmobiliario de renunciar a adquirir su terreno no es la consecuencia necesaria del acto por el que la Administración reduce el programa de construcciones relativo a dicho terreno ${ }^{51}$.

Uno de los pronunciamientos más significativos, en nuestra opinión, si bien se enmarca en un contexto legal sensiblemente distinto, es la Sentencia de 26 de julio de 1985, "Joly Daniel c/. Ministre de l'Urbanisme et du Logement" 52. En este pronunciamiento, el Conseil d'État desestima la acción de responsabilidad presentada por un administrado por los perjuicios sufridos por la imposibilidad de parcelar sus terrenos como consecuencia de una revisión del planeamiento ${ }^{53}$. Los hechos se resumen en la circunstancia de que dicho administrado, después de haber logrado la anulación de un acto ilegal de denegación de una licencia de parcelación, reiteró su solicitud y, de nuevo, se le fue notificada una decisión denegatoria, esta vez fundamentada en la aprobación -durante el periodo que transcurre entre las dos solicitudes- de un nuevo Plan de Ocupación del Suelo, por el que los terrenos en cuestión se transforman en zona natural. Como vemos, un cambio en el planeamiento convierte en imposible la realización de una operación que el administrado hubiera podido realizar si la Administración no se hubiese equivocado inicialmente al no permitirla.

El razonamiento del Conseil d'État nos parece criticable en cuanto se basa en una concepción excesivamente estricta del vínculo de causalidad que ha de existir entre el perjuicio y la conducta de la Administración para que ésta pueda ser declarada responsable. Más precisamente, la concepción que los magistrados privilegian se conoce como la de la "causalidad adecuada", en virtud

\footnotetext{
50 Téngase en cuenta la Sentencia del Conseil d'État de 9 de diciembre de 1984, «Gillet» (Recueil Lebon 509).

51 Vid. la Sentencia del Conseil d'État de 24 de enero de 1970, «Sieur Chodron de Courcel» (Droit Administratif 1970.187).

52 Actualité Juridique. Droit Administratif 1986.46, nota Fatôme; Revue française de droit administratif 1986.470, nota Gilli.

53 Vid. también, en el mismo contexto, la Sentencia de 7 de marzo de 1990, «Ministre de l'Urbanisme et du Logement c/. Bore de Loisy» (Les Petites Affiches, 3 de julio de 1991, p. 19, crón. J.B. Auby).
} 
de la cual, al contrario de lo que se desprende de la denominada "teoría de la equivalencia de condiciones", solamente un acontecimiento puede ser considerado como la causa de un perjuicio y debe ser aquel "que, en el momento de producirse, llevaba en sí mismo normalmente dicho perjuicio" ${ }^{54}$. La Sentencia citada es muy clara en relación con esta cuestión dado que, para motivar su postura, el Conseil d'État destaca que "la imposibilidad en la que (el demandante) se encuentra a la hora de obtener ulteriormente una licencia de parcelación (...) no es la consecuencia directa de la falta cometida por el prefecto" (es decir, la denegación ilegal de la licencia), sino que se debe "a la intervención del plan de ocupación de los suelos (...), que ha clasificado su terreno en zona natural'. No podemos compartir tal argumentación. Es evidente que es la denegación ilegal de la licencia la que provoca la aparición del daño. Para convencerse de ello, basta tener en cuenta que si la Administración se hubiese ajustado a la legalidad vigente al resolver la solicitud de licencia, el particular hubiera podido parcelar su terreno ${ }^{55}$. Defender lo contrario constituye un auténtico sofisma tan poco convincente como, por ejemplo, el que conduce a negar la responsabilidad de una persona culpable de haber empujado a otra persona por debajo de un coche en marcha, alegando que, en realidad, es el vehículo el que ha matado a la víctima, no el autor de la agresión.

Como veremos más adelante, esta interpretación extremadamente rigurosa de la jurisdicción contencioso-administrativa viene reforzada aun más por la amplitud del papel que se reserva al elemento de la culpa de la víctima, como factor de exoneración de la responsabilidad administrativa.

C) El carácter especial y anormal del daño en los casos de responsabilidad sin culpa

Más allá del carácter cierto y directo, el daño sufrido por el particular debe revestir un cierto grado de anormalidad y especialidad cuando el contexto

\footnotetext{
${ }^{54}$ Según dicción literal de las conclusiones del Comisario del Gobierno Galmot relativas a la Sentencia del Conseil d'État de 14 de octubre de 1966, «Marais» (Recueil Dalloz 1966.636). Sobre esta concepción, vid. J.P. TAUGOURDEAU, «Le caractère...», cit., pp. 508 ss. Vid. también, R. CHAPUS, Responsabilité publique et responsabilité administrative, LGDJ, Paris, 1957, pp. 431 ss.; P. ESMEIN, «Le nez de Cléopâtre ou les affres de la causalité», Recueil Dalloz., 1964, crón. no 205. Según la «teoría de la equivalencia de condiciones», por el contrario, la causa de un perjuicio viene constituida por todas las circunstancias que han participado en su realización y sin las cuales dicho perjuicio no se hubiese producido.

${ }^{55}$ Por ello, nos parece más correcto y acertado aplicar la mencionada «teoría de la equivalencia de condiciones», a la que hacemos referencia en el texto y en la nota anterior.
} 
es el de la responsabilidad objetiva de la Administración. El requisito de la especialidad se cumple cuando el daño afecta solamente a ciertos miembros de la colectividad, lo que es señal evidente e inequívoca de que se produce una ruptura de la igualdad ante las cargas públicas. Más precisamente, el daño se considera como especial cuando introduce una discriminación entre el sujeto afectado y los particulares que, encontrándose en las misma situación, no lo sufren. Por otra parte, el requisito de la anormalidad se cumple, según la jurisprudencia, cuando el daño alcanza un cierta relevancia, lo que le impide incluirse en la larga lista de manifestaciones del deber que recae sobre los miembros de la colectividad de soportar sin compensación las molestias y los inconvenientes ordinarios y comunes de la vida en sociedad.

Como ya hemos advertido, la jurisdicción contencioso-administrativa interpreta esta condición muy restrictivamente, en coherencia con su tendencia en lo que se refiere a la puesta en juego de la responsabilidad patrimonial de la Administración pública en materia de urbanismo. Uno de los pocos casos en los que el Conseil d'État ha aceptado reconocer la existencia de un perjuicio especial y anormal es el asunto "Ministre de l'Aménagement du Territoire c/.Navarra" (resuelto por la Sentencia de 20 de marzo de $1974^{56}$ ), en el que se admite la necesidad de resarcir un perjuicio provocado por la edificación, en el campo visual inmediato de una casa antigua, de una construcción edificada sin tener en cuenta las normas de ordenación y los usos estéticos del paraje. Por el contrario, en la Sentencia de 13 de mayo de 1988, "Office public communal d'HLM de Toulon”, los jueces del Palais-Royal consideraron que la pérdida de exposición al sol provocada por la construcción de un bloque de inmuebles colectivos no constituye una molestia superior a las que se expone cualquier propietario de parcela situada en una zona urbanizable, habida cuenta de la posibilidad de que inmuebles colectivos se edifiquen en los terrenos colindantes.

\section{LA IMPUTACIÓN DE LA RESPONSABILIDAD}

\section{A) La identificación de la Administración responsable}

Desde la entrada en vigor de las famosas leyes sobre descentralización administrativa ${ }^{57}$, la Administración pública que asume el mayor peso en materia

\footnotetext{
${ }^{56}$ Recueil Lebon 200, concl. Rougevin-Baville; Recueil Dalloz 1974.481, nota Gilli; Revue de Droit Public 1974.930, nota de Soto.

${ }^{57}$ Nos referimos aquí básicamente a la Ley de 2 de marzo de 1982 y a las setenta Leyes que se aprobaron a continuación.
} 
de responsabilidad patrimonial en el ámbito del urbanismo es el Municipio ${ }^{58}$. En efecto, la competencia de Derecho común en materia de ordenación de los suelos y de las construcciones es esencialmente municipal. Precisamente por ello, se ha ido estableciendo un sistema de seguros del que pueden beneficiarse dichas Entidades locales para cubrir los importantes gastos a los que dan lugar las acciones de responsabilidad, cuando prosperan, y evitar así la aparición de graves problemas financieros ${ }^{59}$.

Sin embargo, la legislación urbanística francesa contempla supuestos en los que la competencia corresponde a la Administración estatal, como, por ejemplo, en materia de comprobación y represión de las infracciones urbanísticas. En otros sectores, el Alcalde, con arreglo a su desdoblamiento funcional, actúa no como autoridad ejecutiva del Municipio sino en nombre o como "agente" del Estado (por ejemplo, cuando otorga ciertas licencias de edificación, cuando dicta una orden de suspensión de obras ilegalmente realizadas, etc.). Pues bien, en ambas circunstancias, la obligación de resarcimiento habrá de imponerse al Estado, no al Municipio. Finalmente, en algunos supuestos, la Administración estatal pone a disposición de los municipios sus servicios especializados en el campo del urbanismo. En principio, habida cuenta de que dichos servicios se someten directamente a la autoridad funcional del Alcalde, la carga de la responsabilidad recaerá sobre el Municipio, lo que no excluye la posibilidad teórica de ejercer una acción de regreso contra el Estado. Sin embargo, la jurisdicción contencioso-administrativa ha precisado que en el caso en que los servicios estatales en cuestión no cumplan las instrucciones dictadas por la autoridad municipal, la responsabilidad se imputará a la Administración del Estado.

B) Los factores de exoneración de la responsabilidad administrativa

\section{La culpa del sujeto perjudicado}

En realidad, la exoneración total o parcial de la responsabilidad administrativa no sólo deriva de la culpa del propio sujeto perjudicado ${ }^{60}$ sino que pue-

58 Vid. L. BRUNEAU, «Le contentieux de l'urbanisme à l'heure de la décentralisation», Etudes Foncières, ํㅜ 34, 1987, pp. 30 ss.

59 Vid. sobre este tema, por ejemplo, F. BOUYSSOU, «L'assurance de la responsabilité communale en matière d'urbanisme», Les Petites Affiches, nํำ 12, 28 de enero de 1985, p. 4.

${ }^{60} \mathrm{Vid}$. sobre este tema, por ejemplo, F. LLORENS-FRAYSSE, «Le poids de la faute dans la responsabilité administrative», Droits, no 5 , 1987, pp. 65 ss. 
de producirse como consecuencia del hecho de un tercero o de la existencia de circunstancias de fuerza mayor. Sin embargo, solamente el primer factor mencionado presenta ciertas características especiales en materia de urbanismo, unas características marcadas, como ya hemos adelantado, por la severidad del juez contencioso-administrativas en su interpretación ${ }^{61}$.

Así, por ejemplo, al igual que en la jurisprudencia española, el Conseil d’État afirma con una severidad evidente que el particular comete una falta cuando presenta una solicitud de licencia que no se ajusta a la legalidad (lo que exonera parcialmente a la Administración de su responsabilidad por otorgamiento ilegal de la licencia) ${ }^{62}$, salvo en el supuesto en que la normativa urbanística resulte particularmente compleja y que, por ello, se pueda presumir la buena fe del solicitante ${ }^{63}$. La misma consideración se aplica a las solicitudes incompletas o defectuosas ${ }^{64}$, no solamente de licencias sino también de certificados de urbanismo.

\section{La "excepción de riesgo aceptado"}

Como su nombre indica y como viene definida por el Conseil d'État, la denominada "excepción de riesgo aceptado" implica que no se deben imputar a la Administración pública (total o parcialmente) los perjuicios previsibles a los que el sujeto perjudicado haya aceptado el riesgo de exponerse de manera voluntaria y consciente ${ }^{65}$.

${ }^{61}$ Vid. H. JACQUOT, Droit.., cit., pp. 677-678. Vid. también, R. SAVY, Droit..., cit., p. 671; J.B. Auby y H. PÉRINET-MARQUET, Droit..., cit., p. 137.

62 Vid. las Sentencias del Conseil d'État de 3 de noviembre de 1972 «Dame Maury» (Recueil Dalloz 1973.761, nota Gilli); de 23 de junio de 1976, «Société de construction immobilière rhodanienne» (Recueil Lebon 1120); y de 14 de marzo de 1990, «Plat» (Les Petites Affiches, 3 de julio de 1991, p. 22, crón. J.B. Auby).

63 Téngase presente la Sentencia del Conseil d'État de 9 de julio de 1982, «Ministre de l'Environnement et du Cadre de Vie c/. Société Le Pré du Roi» (Recueil Lebon 744).

64 Téngase en cuenta la Sentencia del Conseil d'État de 17 de octubre de 1973, «Mouzin-Lizys». Para más supuestos de aplicación de este factor de exoneración de la responsabilidad administrativa, vid. por ejemplo las Sentencias de las Cours administratives d'appel de Bordeaux de 13 de diciembre de 1993, «Anon»; y de Lyon de 28 de febrero de 1995, «Consorts Baudizzone» (Études Foncières 1995.30, crón. Lamorlette).

${ }^{65}$ En la jurisprudencia, para una definición general, vid. la Sentencia del Conseil d'État de 10 de julio de 1996, «Meunier» (Recueil Lebon 289; Droit Administratif 1996, $\mathrm{n}^{\circ}$ 543; Revue de Droit Public 1997.246, concl. Stahl; Revue française de droit administratif 1996.1054). 
En materia de urbanismo, este factor de exoneración no suele formularse o alegarse de manera explícita pero el análisis de diversos pronunciamientos del Conseil d'État revela claramente su utilización. Así, por ejemplo, los jueces del Palais-Royal no dudaron en acudir a la "excepción de riesgo aceptado" para hacer frente a las pretensiones de unas empresas inmobiliarias que habían adquirido unos terrenos con anterioridad a la creación de una "Zona de Ordenación Concertada" ("ZAC") ${ }^{66}$, aceptando el riesgo de que se abandonase el proyecto en cuestión ${ }^{67}$. Por su parte, más recientemente, la Cour administrative d'appel de París acudió a una argumentación similar frente a una empresa que se consideraba perjudicada por la anulación judicial de la decisión de creación de una "ZAC" por su incompatibilidad con el "schéma directeur" de París ${ }^{68}$. En efecto, aun si las circunstancias son distintas en este asunto (en cuanto el proyecto de "ZAC" llegó a aprobarse por la Administración), la jurisdicción considera, lo que nos parece muy riguroso, que la empresa a la que se habían encargado las obras de ordenación no podía ignorar las exigencias del "schéma directeur" en cuestión y la posibilidad de anulación del proyecto, por lo que se exonera a la Administración del $50 \%$ de la responsabilidad ${ }^{69}$.

En el mismo contexto, un profesional del sector inmobiliario afectado por la renuncia de un Municipio a llevar a cabo un proyecto inmobiliario no puede pretender a una indemnización porque no podía ignorar dicho riesgo, a mayor abundamiento cuando la realización del proyecto estaba subordina-

\footnotetext{
${ }^{66}$ Las «ZAC» constituyen zonas cuya urbanización se articula a través de un concierto entre la Administración y empresas privadas.

67 Téngase en cuenta la Sentencia del Conseil d'État de 15 de abril de 1992, «Société Civile Immobilière Vallières» (Recueil Lebon 182; Recueil Dalloz 1992.144, obs. Bon y Terneyre).

68 Vid. la Sentencia de la Cour administrative d'appel de Paris de 27 de noviembre de 2001, «Société financière de la Porte Maillot» (Revue française de droit administratif 2002.421).

69 Los «schémas directeurs» constituyen instrumentos prospectivos y sintéticos que fijan las directrices generales sobre la superficie urbana, la ubicación de las actividades económicas, la conservación de los sitios y paisajes naturales y urbanos, etc., del área afectada (en principio, de ámbito supramunicipal). En definitiva, los «schémas directeurs» se encargan de definir un marco global para las intervenciones urbanísticas futuras, determinando en cierto modo el contenido de los Planes, los cuales, como se desprende de lo que se explica en el texto, deben ser compatibles con su contenido.
} 
da a una modificación del planeamiento y al acuerdo del Pleno ${ }^{70}$. La misma consideración se aplica a la empresa que, teniendo en cuenta las circunstancias, tenía que contemplar la posibilidad de denegación de una licencia de edificación ${ }^{71}$.

70 Téngase presente la Sentencia del Conseil d'État de 16 de noviembre de 1998, «M. Sille» (Recueil Dalloz 1999.15; Revue française de droit administratif 1999.267).

71 Vid. la Sentencia del Conseil d'État de 22 de julio de 1977, «Société nouvelle du Palais des sportsVélodrome d'hiver» (Recueil Lebon 370; Revue de Droit Public 1978.563). 